\title{
Automatic Reminder for Fluids Management on Confidence and Compliance with Fluid Restrictions in Hemodialysis Patients
}

N ursalam N ursalam ${ }^{1}$, Ninuk Dian Kurniawati ${ }^{1}$, Inda Rian Patma Putri ${ }^{1}$, Diah Priyantini ${ }^{1}$

${ }^{1}$ Faculty of Nursing, Universitas Airlangga, Surabaya, Indonesia

\begin{abstract}
Article History: ABSTRACT

Discharge planning has not been able to increase confidence and fluid restriction adherence in endstage renal failure patients undergoing hemodialysis. This study aimed to develop an application of discharge planning with automatic reminder of fluid management to improve fluid restriction adherence in hemodialysis patients. Research and development with the first stage was developing an application prototype by evaluating hemodialysis patients' issues through interviews and questionnaires of 115 respondents. Focus group discussions with health professionals and expert discussions were conducted after data collecting. Second stage was a quasiexperimental study with 30 respondents in each group using simple random sampling. Research analysis used MANOVA test. The development of a prototype consisted of pooling intake, pooling output, fluid control log, education, setting and automatic fluid monitoring reminder. The results of interviews with the target users showed that the app was feasible. The effect of interventions on
\end{abstract}

Revised: 09.04.2020

Accepted: 10.05 .2020

beliefs (perceived threat, perceived benefit, perceived barrier, and self-efficacy) with $p=0.001$, fluid restriction compliance and IDWG $p$ $=0.001$ after the intervention using the development of discharge planning with automatic reminder app. Development of discharge planning with automatic reminder of fluid management consists of several menus and the main feature was an automatic fluid monitoring reminder. This app can increase self-confidence in fluid restriction and adherence in patients undergoing hemodialysis.

Keywords: Adherence, ALISA, fluid management, hemodialysis, mhealth, reminder, smartphone.

Correspondence

Nursalam Nursalam

Faculty of Nursing, Universitas Airlangga, Surabaya, Indonesia

E-mail: nursalam@fkp.unair.ac.id

DOI: $10.31838 /$ srp. 2020.5.34

@Advanced Scientific Research. All rights reserved

\section{INTRODUCTION}

Endstage chronic kidney disease is a progressive and irreversible loss of kidney function and inability to maintain metabolic, fluid and electrolyte balance, resulting in uremia [1]. The most common renal function replacement therapy in patients with kidney failure is hemodialysis [2] and its success is influenced by patient's adherence to therapy, restrictions on fluid intake, diet, treatment and control schedules [3]. The most common problem is that patients do not comply with fluid intake restrictions, thus requiring effective education to increase knowledge [4]. Patient's knowledge when leaving the hospital is an important element that must be fulfilled, because it affects care when at home. Discharge planning is the right tool, but the implementation is still not optimal [5].

The prevalence of patients with end-stage kidney failure in the world is as many as 661,648 people and poses a global health threat. In Indonesia, the number of kidney failure patients is around $0.2 \%$ and as many as $98 \%$ of patients undergo hemodialysis therapy [1,4]. The level of noncompliance with hemodialysis patients in limiting fluid intake reaches $79.5 \%$ in America, Germany, Belgium and Ireland [6]. Similarly, in China the number of noncompliance patients with hemodialysis to fluid restriction ranges from 43.6 - 54.9\% [7]. The high number of noncompliance is due to the low level of knowledge obtained by the patient. In Indonesia, it was found that the discharge was carried out in a simple manner orally, in conjunction with hemodialysis, on matters that need to be remembered by patients about the necessity to restrict fluid so that there is no excess fluid; thus patients did not remember much [8].

Patients' noncompliance with fluid restriction can cause hypervolemia, resulting in excessive circulation burden, edema, cardiovascular disorders, impaired cognitive function and death [9]. Lack of information is a factor that contributes to non-compliance with therapeutic regimens, especially restrictions on fluid and sodium intake, which can cause increased morbidity [10]. For the success of hemodialysis to be achieved, good quality care is needed by health workers, by involving patients and families in understanding the disease and therapeutic regimens arranged in discharge planning [11]. Patient education is the duty and responsibility of nurses and an important component in the quality of nursing [12]. Previous studies have reported that patient education and self-monitoring methods effectively improve the compliance of hemodialysis patients with fluid and dietary restrictions $[13,14]$.

Rapid technological advances have made applications in smartphones as a potential tool to improve adherence to treatment $[15,16]$. Several studies have been conducted to prove information technology-based interventions improve self-management and compliance behavior in patients with chronic illness [17]. Based on the above problems, the researchers are interested in conducting research into the development of discharge planning with an Android-based automatic fluid management reminder. This study uses the Health Belief model approach, where behavioral change is influenced by four components: (1) perceived susceptibility of the disease; (2) perceived severity of the disease; (3) perceived benefit of implementing the recommended fluid restriction; and (4) perceived barrier in limiting the fluid [18]. This study aimed to develop an application of discharge planning with automatic reminder of fluid management to improve fluid restriction adherence in hemodialysis patients.

\section{METHODS}

Research and development studies function to validate and develop products. This research focused to develop discharge planning with an Android system-based automatic fluid reminder management. The problem identification in phase 1 used an exploratory descriptive design for the evaluation of discharge planning at the 
hospital and an evaluation of the knowledge, beliefs and compliance of chronic kidney disease (CKD) patients undergoing hemodialysis of fluid recording. The sample in this stage was 115 patients with CKD who underwent hemodialysis criteria $>21$ years old, underwent regular hemodialysis twice in a week, could communicate well verbally, could read, write and speak Indonesian well and did not experience cognitive or mental disorders. Data collected were used modified instrument of demographic, adherence and discharge planning questionnaire. The data collected were used to find strategic issues based on the results of the exploration of the facts from the questionnaire and the results of interviews. Then, an expert discussion was conducted to explore expert opinion and input in developing discharge planning content with automatic reminder for fluid management through the Android smartphone application.

The development of the Automatic Alarm Fluid Control Hemodialysis or called ALISA was an Android operating system-based application designed as a medium for selfmonitoring and automatic reminders in fluid management and education for patients undergoing hemodialysis. The application was installed on an Android-based smartphone. The application had a fluid intake and output menu, a fluid control chart, HD Control, Health Education and settings. This tool works like a smartphone application and was used by patients in their daily lives to remind their daily schedule.Stage 2 was a quasi-experiment with pre-posttest design with 27 CKD patients as a sample through simple random sampling who underwent hemodialysis with criteria $>21$ years old, underwent hemodialysis $>3$ months, had and could use an Android smartphone, underwent regular hemodialysis twice in a week, could read, write and speak Indonesian well and were not experiencing severe cognitive impairment. Modified hemodialysis compliance behavior questionnaire from Hediyanti (2017) was used regarding compliance measures in fluid restriction. Multivariate tests were performed using MANOVA to measure the effect of categorical data interventions on numerical scale beliefs, compliance and IDWG. This study has passed the ethical review conducted by the $\mathrm{H}$ ealth Research Ethics Committee of Sidoarjo District General Hospital with the Research Ethics Eligibility number: 893.3/0484/438.6.7/2019 dated February 6, 2019.

\section{RESULTS}

Demographic of Respondents' Characteristics in First Stage

The majority respondent's characteristics were male (70/115, 60.9\%) and aged 36-45 years (39/115, 33.9\%). M ost respondents did not work (84/115, 73.0\%). Respondents with hemodialysis duration between 1-3 years were higher than others $(44 / 115,38.3 \%)$ and the predominant last education was senior high school (60/115, 52.2\%) (Table 1 ).

Table 1: Data Demographic of Respondents in First Stage to Development of Discharge Planning with Automatic Reminder for Fluid $M$ anagement

\begin{tabular}{lll}
\hline Respondent Characteristics & N & $\%$ \\
\hline Gender & 70 & \\
M ale & 45 & 60.9 \\
Female & & 39.1 \\
Age & 3 & \\
$21-25$ years & 9 & 2.6 \\
$26-35$ years & 39 & 7.8 \\
36-45 years & 33 & 33.9 \\
$46-55$ years & 31 & 28.7 \\
56-65 years & & 27.0 \\
Marital Status & 99 & \\
M arried & 15 & 86.1 \\
Single & & 13.0 \\
Educational Background & 16 & 13.9 \\
Elementary School & 23 & 20.0 \\
Junior High School & 60 & 52.2 \\
Senior High School & 16 & 13.9 \\
Bachelor & & \\
Occupation & 31 & 27.0 \\
Employee & 84 & 73.0 \\
N ot working & & \\
Hemodialysis duration & 31 & 27.0 \\
3-12 months & 44 & 38.3 \\
>1-3 years & 24 & 20.9 \\
>3-5 years & 16 & 13.9 \\
$>5$ years &
\end{tabular}

The Evaluation of D ischarge Planning 
The implementation of health education for patients when discharge planning conducted was good categories in medication $(84 / 115,74.8 \%)$, treatment $(81 / 115,70.4 \%)$, outpatient referral $(112 / 115,97.4 \%)$ and lack categories in health teaching $(78 / 115,67.8 \%)$, environment $(53 / 115$, $46.1 \%)$ and diet $(61 / 115,53 \%)$. In the aspect of diet, education for fluids management was only given when there was an excess fluid problem. Most respondents said providing education in discharge was done when the patient asks about abnormal clinical results, such as high blood pressure and poor lab results. Patients said that they need for regular and easily understood health education for an understanding of their condition (Table 2).

Table 2: The Evaluation of Discharge Planning Implementation in Hospital

\begin{tabular}{|c|c|c|}
\hline Respondents' Characteristics & $\mathbf{N}$ & $\%$ \\
\hline \multicolumn{3}{|l|}{ Medication } \\
\hline Good & 86 & 74.8 \\
\hline Moderate & 13 & 10.4 \\
\hline Bad & 16 & 13.9 \\
\hline \multicolumn{3}{|l|}{ Environment } \\
\hline Good & 30 & 26.1 \\
\hline Moderate & 32 & 27.8 \\
\hline Bad & 53 & 46.1 \\
\hline \multicolumn{3}{|l|}{ Treatment } \\
\hline Good & 81 & 70.4 \\
\hline M oderate & 23 & 20.0 \\
\hline Bad & 11 & 9.6 \\
\hline \multicolumn{3}{|l|}{ Health Teaching } \\
\hline Good & 13 & 11.3 \\
\hline M oderate & 24 & 20.9 \\
\hline Bad & 78 & 67.8 \\
\hline \multicolumn{3}{|l|}{ Outpatient Referral } \\
\hline Good & 112 & 97.4 \\
\hline M oderate & 24 & 2.6 \\
\hline Bad & 0 & 0.0 \\
\hline \multicolumn{3}{|l|}{ Diet } \\
\hline Good & 33 & 28.7 \\
\hline Moderate & 21 & 18.3 \\
\hline Bad & 61 & 53.0 \\
\hline
\end{tabular}

\section{The Evaluation of Knowledge}

M ost respondents had sufficient knowledge (43/115, 37.4\%) about chronic kidney disease in general. In evaluating beliefs, some respondents had positive beliefs related to perceived vulnerability and perceived threat (61/115, $53.0 \%)$. From the variable of confidence in the perceived benefit, some respondents showed positive belief in the benefits of obeying liquid restrictions (59/115, 51.3\%), and the perceived barrier showed high confidence in the obstacles $(61 / 115,53.0 \%)$. M ost respondents had low selfefficacy $(64 / 115,55.7 \%)$ and the majority of respondents' compliance with fluid restriction was still lacking $(62 / 115$, 53.9\%) (Table 3).

Table 3: The Evaluation of Patients' Knowledge

\begin{tabular}{lcc}
\hline \multicolumn{2}{c}{ Nespondents' Characteristics } & $\%$ \\
\hline Knowledge & 41 & 35.7 \\
Good & 43 & 37.4 \\
Moderate & 31 & 27.0 \\
Bad & & \\
Belief & & \\
Perceived treat & 61 & 53.0 \\
Positive & 54 & 47.0 \\
Negative & & \\
Perceived benefit & 59 & 51.3 \\
Positive &
\end{tabular}


Negative

Perceived barrier

High

Low

\section{Self-efficacy}

Positive

Negative

Compliance

Good

M oderate

$\mathrm{Bad}$
56

$61 \quad 53.0$

$54 \quad 47.0$

$51 \quad 44.3$

$64 \quad 55.7$

$33 \quad 28.7$

$21 \quad 18.3$

$61 \quad 53.0$
The Recommendation of Focus Group and Expert Discussion

Recommendations from discussion to development of discharge planning with automatic reminder for fluid management were: (1) Health education material according to patient needs in managing fluid; (2) Discharge planning media must be effective and efficient; (3) Active reminders to encourage patients to monitor fluids at home; (4) Facilities to monitor fluid intake and body weight for each dialysis session; and (5) The method can increase patient confidence and compliance in fluid management.

After conducting FGD, researchers conducted expert discussions with recommendations: (1) A pplication of health education features is made interesting with simple and easy to understand instructions; (2) The application can be used in both online and offline mode; (3) Make guidelines for application usage that are easy to understand; (4) Dissemination and training on the use of application development with automatic reminder for fluid management.

Demographic of Respondents' Characteristics in Second Stage

Table 4: Data Demographic of Respondents in Second Stage to Development of Discharge Planning with Automatic Reminder for Fluid $M$ anagement

\begin{tabular}{|c|c|c|c|c|c|}
\hline \multirow{2}{*}{ Respondent Characteristics } & \multicolumn{2}{|c|}{ Intervention } & \multicolumn{2}{|c|}{ Control } & \multirow{2}{*}{ Homogeneity } \\
\hline & $\bar{\Sigma}$ & $\%$ & $\Sigma$ & $\%$ & \\
\hline \multicolumn{6}{|l|}{ Gender } \\
\hline Male & 17 & 56.7 & 22 & 71 & 0.884 \\
\hline Female & 13 & 43.3 & 9 & 29 & \\
\hline \multicolumn{6}{|l|}{ Age } \\
\hline $21-25$ years & 2 & 6.7 & 2 & 6.5 & \\
\hline $26-35$ years & 5 & 16.7 & 2 & 6.5 & 0.182 \\
\hline $36-45$ years & 10 & 33.3 & 10 & 32.3 & \\
\hline $46-55$ years & 6 & 20.0 & 9 & 29.0 & \\
\hline $56-65$ years & 7 & 23.3 & 8 & 25.8 & \\
\hline \multicolumn{6}{|l|}{ Marital Status } \\
\hline M arried & 5 & 16.7 & 4 & 12.9 & \\
\hline Single & 25 & 83.3 & 26 & 87.1 & 0,112 \\
\hline \multicolumn{6}{|l|}{ Educational Background } \\
\hline Elementary School & 5 & 16.7 & 11 & 35.5 & \\
\hline Junior High School & 18 & 60 & 16 & 51.6 & 0.155 \\
\hline Senior High School & 7 & 23.3 & 4 & 12.9 & \\
\hline \multicolumn{6}{|l|}{ Occupation } \\
\hline Not working & 21 & 70 & 21 & 71 & 0,104 \\
\hline Employee & 9 & 30 & 9 & 29 & \\
\hline \multicolumn{6}{|l|}{ H emodialysis duration } \\
\hline 3-12 months & 6 & 20 & 8 & 25.8 & 0.135 \\
\hline$>1-3$ years & 18 & 60 & 10 & 32.3 & \\
\hline$>3-5$ years & 3 & 10 & 8 & 25.8 & \\
\hline$>5$ years & 3 & 10 & 5 & 16.1 & \\
\hline
\end{tabular}

Regarding the characteristics of the respondents, almost half of them were aged between 36-45 years (Intervention vs.
Control, $33.3 \%$ vs. $32.3 \%$, respectively). The majority of respondents, both in intervention and control group, were 
married with a percentage of $62.5 \%$ and $87.1 \%$. The level of education in the intervention group and the control group was mostly junior high school (Intervention vs. Control; $60 \%$ vs. $51.6 \%$ ). The length of undergoing hemodialysis in the intervention group was mostly between $1-3$ years $(60 \%)$, and in the control group it was almost partly between $1-3$ years $(32.3 \%)$ and the majority of respondents did not work (Table4).

Multivariate Test Analysis

Table 5: M ultivariateT est Analysis of Discharge Planning A pplication Development with Automatic Reminder for Fluid $M$ anagement.

\begin{tabular}{|c|c|c|c|c|c|c|c|}
\hline \multirow[b]{2}{*}{ Effect } & & \multirow[b]{2}{*}{ Value } & \multirow[b]{2}{*}{$\mathbf{F}$} & \multirow[t]{2}{*}{ Hypothesisdf } & \multicolumn{2}{|l|}{ Error df } & \multirow{2}{*}{$\begin{array}{l}\text { Partial Eta } \\
\text { Squared }\end{array}$} \\
\hline & & & & & & Sig. & \\
\hline \multirow[t]{4}{*}{ Group } & Pillai's trace & .774 & $30.826 b$ & 6.000 & 54.000 & 0.000 & .774 \\
\hline & Wilks'Lambda & .226 & $30.826 b$ & 6.000 & 54.000 & 0.000 & .774 \\
\hline & Hotelling's Trace & 3.425 & $30.826 b$ & 6.000 & 54.000 & 0.000 & .774 \\
\hline & Roy's Largest R & 3.425 & $30.826 b$ & 6.000 & 54.000 & 0.000 & .774 \\
\hline
\end{tabular}

The results of the analysis show that the group $F$ price for Pillai's Trace, Wilks' Lambda, Hotelling's Trace and Roy's Largest Root have a significance value of $p 0.001$ ( $p<0.05$ ), this indicates that the $F$ price for all is significant. There are differences in the variables of belief (perceived threat, perceived benefit, perceived barrier, self-efficacy) and compliance (IDWG and actions) in all variables with a difference of $77.4 \%$. There is a significant influence on the development of discharge planning interventions with automatic reminder of fluid management in the components of confidence (threat, benefit, barrier, efficacy) and compliance (IDWG) in patients undergoing hemodialysis (Table 5).

\section{Discharge Planning with Automatic Reminder of Fluid Management}

After the intervention application, the development of discharge planning with automatic reminder of fluid management for confidence and compliance with fluid restriction, all respondents (100\%) stated that the feasibility of the application of ALISA (Automatic Fluid Control Hemodialysis) in the respondent's perspective was good, viewed from the aspects of function, efficiency, feasibility and ease of use. The application is considered to be able to achieve the goal as a medium of self-monitoring in improving compliance with fluid restrictions and educational facilities in hemodialysis patients. Respondents had no difficulty in using the application; the application can be used efficiently.

The content in the application also greatly helped respondents in increasing compliance with fluid restrictions and recording daily data for weight and blood pressure. In terms of security, the use of applications is very safe because there is a register procedure for new users and it is accompanied by a password so that patient data are recorded on the application server and the data stored on the server so that, if there is damage to the user's device, the data are still stored.

\section{DISCUSSION}

Compilation of the development of discharge planning with automatic reminder for fluid management for patients undergoing hemodialysis is done by finding strategic issues addressed in the FGD with health professionals in hospitals consisting of multidisciplinary science. This strategic issue was obtained from structured interviews with patients about discharge education as well as evaluating the patients' knowledge, beliefs and compliance with fluid restriction through a questionnaire. The results of the FGDs showed that there were several strategic issues, such as the implementation of discharge planning in the aspects of health teaching and the provision of education related to a diet that was still lacking; there was no effective media for health education, there were still patients who lacked knowledge, patient confidence in barriers was mostly high, low self-efficacy, and most patients showed low levels of fluid restriction compliance.

In providing health education to patients, it is necessary to pay attention to educational methods and materials as well as adjustments to recipients' education. During this time, the implementation of health education was only done verbally and the material delivered was only given in a relatively short time. Effective media to conduct discharge education by nurses are not yet available, existing media are in the form of leaflets that only contain general health information. Efforts have been made to facilitate the fulfillment of educational needs with media leaflets, brochures, counseling; however, despite these efforts patients still show low dietary compliance $[14,19]$.

Technological advances have developed and the rapid development of smartphones has made applications in smartphones as a potential tool to improve adherence to treatment $[20,21]$. With the global prevalence of mobile technology, accessing health-related applications via mobile phones can be an approach to promoting patient involvement in health [22]. Several studies have been conducted to prove IT-based interventions improve selfmanagement and compliance behavior in patients with chronic illness. Research into web-based automatic SMS reminder interventions about medication warnings and health education in cardiovascular patients states that interventions show good results on adherence in drug consumption in heart disease patients' diet compliance [23].

Research conducted using PDAs (personal digital assistants) has been proven to reduce dietary sodium intake in patients, although there is no significant change in IDWG [24]. Smartphone applications are proven to be feasible and 
acceptable to support self-management of patients. Patient education and self-monitoring methods effectively improve hemodialysis patient compliance with fluid and dietary restrictions [25]. Based on the current literature showing a positive trend for the use of eHealth in chronic disease management and changes in health behaviors, it can be estimated that the CKD population can also benefit from the use of eHealth interventions [26]. E-Health interventions are seen as a viable option for promoting behavioral change, disease management and clinical improvement. There are promising results from using eH ealth interventions, when used in addition to traditional counseling techniques, to improve disease management in chronic disease populations [7].

Researchers developed a discharge planning application with automatic reminder based on the results of the literature, FGD and expert discussion. Recommendations from the FGD for efforts to increase patient confidence and compliance is to develop an effective and efficient method, which is easy to do and can provide encouragement for patients on a regular basis to manage fluid; the method of using this Android application is deemed appropriate to meet the needs in educational discharge and increasing patient confidence and compliance. This is in line with qualitative research which states that, although hemodialysis patients feel they know what to do, they still need reminders to keep them motivated in following recommendations for dietary food or fluid restriction [27].

Development designed by researchers is presented and offered to participants. This application is an android system-based application that can be installed on a smartphone. This application is not yet available on Google Play Store, but the installation of the application can be done via manual share. This application contains six main menus, namely pooling intake, pooling output, fluid control log, health education, HD control and settings. A utomatic reminder contains information on the exact amount of liquid that can be consumed every day and there are motivational sentences to limit fluid. This was created as an encouraging signal for patients to do fluid restriction. This application can be used offline or online for users who do not have an internet connection. There is a special "HD control" menu for weight and blood pressure recording journals, but their use can only be done online. This application uses an official database server that maintains the security of user data. All data will be encrypted on the server, this also provides its own benefits in monitoring all patient data.

A pplication interventions for developing discharge planning with an automatic reminder emphasize confidence in the benefits of fluid management, confidence in decreasing perceived barriers in limiting fluids and confidence in health education given to indicate changes in action. If an individual considers themselves vulnerable to a condition, believes that the condition will have serious consequences, believes that an action is available to them and will be beneficial in reducing their vulnerability or severity of the condition experienced, and believes in the anticipated benefit of taking action greater than the obstacles to action, then they will tend to take actions that they believe will reduce risk $[20,28]$. This is in line with research conducted using a medication reminder application for patients with heart disease which found that adherence to taking medication in patients was higher than in the control group [29].

Development of discharge planning with automatic reminder also reduces the perceived barriers; the patient's perception of barriers to limiting fluid decreases with an application that makes it easy for patients to monitor fluids, and provides driving cues in the form of daily reminders that provide motivation for patients so as to enable open behavior in conducting fluid restriction [21,22]. Compliance with fluid restrictions manifests in behavior health, which, in this study, was obtained from the score of fluid restriction and IDWG measures. After the intervention using the development discharge planning with automatic reminder of fluid management application, the score of the fluid restriction measures increased and the IDWG in the treatment group decreased. The limitation of this study is the application cannot be used in patients who do not have an Android-based smartphone application. Data that have been filled in by respondents is not automatically seen by nurses because the data are stored on a server held by the researcher.

\section{CONCLUSION}

Development of discharge planning automatic fluid management reminder based on Android increases the confidence and compliance of patients undergoing hemodialysis in fluid restriction measures resulting in a decrease in IDWG. This application consists of a health education menu, a fluid monitoring menu (pooling intake and pooling output), info on fluid status graphs, HD controls, and automatic fluid management reminder features.

\section{REFERENCES}

1. A mmirati AL. Chronic kidney disease. V ol. 66, Revista da Associacao Medica Brasileira. 2020. p. 3-9.

2. Redmon JH, Elledge MF, Womack DS, W ickremashinghe $R$, Wanigasuriya KP, Peiris-John $\mathrm{RJ}$, et al. Additional perspectives on chronic kidney disease of unknown aetiology (CKDu) in Sri Lanka Lessons learned from the WHO CKDu population prevalence study. BMC N ephrol. 2014;15(1).

3. Kang HM, Ahn SH, Choi P, Ko YA, Han SH, Chinga $F$, et al. Defective fatty acid oxidation in renal tubular epithelial cells has a key role in kidney fibrosis development. Nat M ed. 2015;21(1):37-46.

4. Martin A, M acdonald J, M oore J. Renal failure and its treatment. Vol. 16, Anaesthesia and Intensive Care M edicine. 2015. p. 267-74.

5. Murphy D, M cCulloch CE, Lin F, Banerjee T, BraggGresham JL, Eberhardt MS, et al. Trends in prevalence of chronic kidney disease in the United States. Ann Intern M ed. 2016;165(7):473-81.

6. Gaitonde DY, Cook DL, Rivera IM. Chronic Kidney Disease: Detection and Evaluation. Am Fam Physician. 2017;96(12):776-83.

7. Zhang $L, W$ ang $F, W$ ang $L, W$ ang $W$, Liu $B$, Liu J, et 
al. Prevalence of chronic kidney disease in China: A cross-sectional survey. Lancet. 2012;379(9818):81522.

8. Centers for Disease Control and Prevention. National Chronic Kidney Disease Fact Sheet 2017. US Dep H eal Hum Serv Cent Dis Control Prev. 2017;

9. Chawla LS, Eggers PW, Star RA, Kimmel PL. A cute kidney injury and chronic kidney disease as interconnected syndromes. Vol. 371, New England Journal of M edicine. 2014. p. 58-66.

10. Zhu QM, Liu J, Hu HY, Wang S. Effectiveness of nurse-led early discharge planning programmes for hospital inpatients with chronic disease or rehabilitation needs: A systematic review and metaanalysis. J Clin Nurs. 2015;24(19-20):2993-3005.

11. Hooi LS, Ong LM, Ahmad G, Bavanandan S, Ahmad NA, Naidu BM, et al. A population-based study measuring the prevalence of chronic kidney disease among adults in West Malaysia. Kidney Int. 2013;84(5):1034_40.

12. Stevenson KN, Jack SM, O'Mara L, LeGris J. Registered nurses' experiences of patient violence on acute care psychiatric inpatient units: An interpretive descriptive study. BM C Nurs. 2015;14(1).

13. Lee $Y$ J, Shin SJ, W ang RH, Lin K Der, Lee $Y L$, Wang $\mathrm{YH}$. Pathways of empowerment perceptions, health literacy, self-efficacy, and self-care behaviors to glycemic control in patients with type 2 diabetes mellitus. Patient Educ Couns. 2016;99(2):287-94.

14. Brock D, A bu-Rish E, Chiu CR, Hammer D, W ilson S, Vorvick $L$, et al. Interprofessional education in team communication: Working together to improve patient safety. BM J Q ual Saf. 2013;22(5):414-23.

15. Benton K, Camp LJ, Garg V. Studying the effectiveness of android application permissions requests. In: 2013 IEEE International Conference on Pervasive Computing and Communications W orkshops, PerCom Workshops 2013. 2013. p. 2916.

16. De Boer RA, Daniels LB, Maisel AS, Januzzi JL. State of the Art: N ewer biomarkers in heart failure. Eur J Heart Fail. 2015;17(6):559_69.

17. Abtahi F, Berndtsson A, Abtahi S, Seoane F, Lindecrantz $K$. Development and preliminary evaluation of an Android based heart rate variability biofeedback system. In: 2014 36th Annual International Conference of the IEEE Engineering in Medicine and Biology Society, EM BC 2014. 2014. p. 3382-5.

18. Goldenberg J L, Arndt J. The Implications of Death for Health: A Terror Management Health Model for Behavioral Health Promotion. Psychol Rev. 2008;115(4):1032-53.

19. Antheunis ML, Tates $K$, Nieboer TE. Patients' and health professionals' use of social media in health care: Motives, barriers and expectations. Patient Educ Couns. 2013;92(3):426-31.

20. AlKlayb SA, Assery MK, AIQ ahtani A, AIA nazi M, Pani SC. Comparison of the effectiveness of a mobile phone-based education program in educating mothers as oral health providers in two regions of Saudi Arabia. J Int Soc Prev Community Dent. 2017;7(3):110-5.

21. M owad M, Fathy A, H afez A. Smart home automated control system using android application and microcontroller. Int J Sci Eng Res. 2014;5(5):935-9.

22. Sung YT, Chang KE, Liu TC. The effects of integrating mobile devices with teaching and learning on students' learning performance: A meta-analysis and research synthesis. Comput Educ. 2016;94:252-75.

23. Schwebel FJ, Larimer ME. Using text message reminders in health care services: $A$ narrative literature review. Vol. 13, Internet Interventions. 2018. p. 82-104.

24. Scheelbeek PFD, Chowdhury MAH, Haines A, Alam $D S$, Hoque MA, Butler AP, et al. Drinking water salinity and raised blood pressure: Evidence from a cohort study in coastal Bangladesh. Environ Health Perspect. 2017;125(5).

25. Radovic A, Vona PL, Santostefano AM, Ciaravino S, Miller E, Stein BD. Smartphone Applications for Mental Health. Cyberpsychology, Behav Soc Netw. 2016;19(7):465-70.

26. Poppe L, Van Der Mispel C, De Bourdeaudhuij I, Verloigne M, Shadid S, Crombez G. Users' thoughts and opinions about a self-regulation-based eH ealth intervention targeting physical activity and the intake of fruit and vegetables: A qualitative study. PLoS O ne. 2017;12(12).

27. Horvath JDC, de Castro MLD, Kops N, Kruger Malinoski N, Friedman R. ¿Obesidad coexiste con la desnutrición? adecuación del consumo de alimentos de los pacientes obesos a las recomendaciones de ingesta dietética de referencia. Nutr Hosp. 2014;29(2):292-9.

28. Dinicolantonio JJ, Niazi AK, Sadaf R, O’Keefe JH, Lucan SC, Lavie CJ. Dietary sodium restriction: Take it with a grain of salt. $\mathrm{V}$ ol. 126, American Journal of M edicine. 2013. p. 951-5.

29. Santo K, Chow CK, Thiagalingam A, Rogers K, Chalmers J, Redfern J. M EDication reminder APPs to improve medication adherence in Coronary Heart Disease (MedApp-CHD) Study: A randomised controlled trial protocol. BMJ Open. 2017;7(10).

30. A mmirati AL. Chronic kidney disease. V ol. 66, Revista da Associacao M edica Brasileira. 2020. p. 3-9.

31. Redmon JH, Elledge MF, Womack DS, W ickremashinghe $R$, W anigasuriya $K P$, Peiris-John $\mathrm{RJ}$, et al. Additional perspectives on chronic kidney disease of unknown aetiology (CKDu) in Sri Lanka Lessons learned from the WHO CKDu population prevalence study. BMC N ephrol. 2014;15(1).

32. Kang HM, Ahn SH, Choi P, Ko YA, Han SH, Chinga $F$, et al. Defective fatty acid oxidation in renal tubular epithelial cells has a key role in kidney fibrosis development. Nat M ed. 2015;21(1):37-46.

33. Martin A, M acdonald J, Moore J. Renal failure and its treatment. Vol. 16, Anaesthesia and Intensive Care Medicine. 2015. p. 267-74.

34. Murphy D, M cCulloch CE, Lin F, Banerjee T, Bragg- 
Gresham JL, Eberhardt M S, et al. Trends in prevalence of chronic kidney disease in the United States. Ann Intern M ed. 2016;165(7):473-81.

35. Gaitonde DY, Cook DL, Rivera IM. Chronic Kidney Disease: Detection and Evaluation. Am Fam Physician. 2017;96(12):776-83.

36. Zhang $L, W$ ang $F, W$ ang $L, W$ ang $W$, Liu $B$, Liu J, et al. Prevalence of chronic kidney disease in China: A cross-sectional survey. Lancet. 2012;379(9818):815 22.

37. Centers for Disease Control and Prevention. National Chronic Kidney Disease Fact Sheet 2017. US Dep H eal H um Serv Cent Dis Control Prev. 2017;

38. Chawla LS, Eggers PW, Star RA, Kimmel PL. Acute kidney injury and chronic kidney disease as interconnected syndromes. Vol. 371, New England Journal of M edicine. 2014. p. 58-66.

39. Zhu QM, Liu J, Hu HY, Wang S. Effectiveness of nurse-led early discharge planning programmes for hospital inpatients with chronic disease or rehabilitation needs: A systematic review and metaanalysis. J Clin N urs. 2015;24(19-20):2993-3005.

40. Hooi LS, Ong LM, Ahmad G, Bavanandan S, Ahmad NA, Naidu BM, et al. A population-based study measuring the prevalence of chronic kidney disease among adults in West Malaysia. Kidney Int. 2013;84(5):1034-40.

41. Stevenson KN, Jack SM, O'Mara L, LeGris J. Registered nurses' experiences of patient violence on acute care psychiatric inpatient units: An interpretive descriptive study. BM C Nurs. 2015;14(1).

42. Lee YJ, Shin SJ, Wang RH, Lin K Der, Lee YL, Wang $\mathrm{YH}$. Pathways of empowerment perceptions, health literacy, self-efficacy, and self-care behaviors to glycemic control in patients with type 2 diabetes mellitus. Patient Educ Couns. 2016;99(2):287-94.

43. Brock D, A bu-Rish E, Chiu CR, H ammer D, Wilson S, Vorvick $L$, et al. Interprofessional education in team communication: W orking together to improve patient safety. BM J Qual Saf. 2013;22(5):414-23.

44. Benton K, Camp LJ, Garg V. Studying the effectiveness of android application permissions requests. In: 2013 IEEE International Conference on Pervasive Computing and Communications Workshops, PerCom Workshops 2013. 2013. p. 291 6.

45. De Boer RA, Daniels LB, M aisel AS, Januzzi JL. State of the Art: N ewer biomarkers in heart failure. Eur J H eart Fail. 2015;17(6):559-69.

46. Abtahi F, Berndtsson A, Abtahi S, Seoane F, Lindecrantz $K$. Development and preliminary evaluation of an Android based heart rate variability biofeedback system. In: 2014 36th Annual International Conference of the IEEE Engineering in Medicine and Biology Society, EM BC 2014. 2014. p. 3382-5.
47. Goldenberg JL, Arndt J. The Implications of Death for Health: A Terror Management Health Model for Behavioral Health Promotion. Psychol Rev. 2008;115(4):1032-53.

48. Antheunis ML, Tates K, Nieboer TE. Patients' and health professionals' use of social media in health care: Motives, barriers and expectations. Patient Educ Couns. 2013;92(3):426-31.

49. AlKlayb SA, Assery MK, AIQahtani A, AIAnazi M, Pani SC. Comparison of the effectiveness of a mobile phone based education program in educating mothers as oral health providers in two regions of Saudi Arabia. J Int Soc Prev Community Dent. 2017;7(3):110-5.

50. M owad M, Fathy A, H afez A. Smart home automated control system using android application and microcontroller. Int J Sci Eng Res. 2014;5(5):935-9.

51. Sung YT, Chang KE, Liu TC. The effects of integrating mobile devices with teaching and learning on students' learning performance: A meta-analysis and research synthesis. Comput Educ. 2016;94:252-75.

52. Schwebel FJ, Larimer ME. Using text message reminders in health care services: A narrative literature review. V ol. 13, Internet Interventions. 2018. p. 82-104.

53. Scheelbeek PFD, Chowdhury MAH, Haines A, Alam $D S$, Hoque $M A$, Butler $A P$, et al. Drinking water salinity and raised blood pressure: Evidence from a cohort study in coastal Bangladesh. Environ Health Perspect. 2017;125(5).

54. Radovic A, Vona PL, Santostefano AM, Ciaravino S, Miller $E$, Stein BD. Smartphone Applications for Mental Health. Cyberpsychology, Behav Soc Netw. 2016;19(7):465-70.

55. Poppe L, Van Der Mispel C, De Bourdeaudhuij I, Verloigne M, Shadid S, Crombez G. Users' thoughts and opinions about a self-regulation-based eH ealth intervention targeting physical activity and the intake of fruit and vegetables: A qualitative study. PLoS O ne. 2017;12(12).

56. Horvath JDC, de Castro MLD, Kops N, Kruger Malinoski N, Friedman R. ¿Obesidad coexiste con la desnutrición? adecuación del consumo de alimentos de los pacientes obesos a las recomendaciones de ingesta dietética de referencia. Nutr Hosp. 2014;29(2):292-9.

57. Dinicolantonio J, Niazi AK, Sadaf R, O'Keefe JH, Lucan SC, Lavie CJ. Dietary sodium restriction: Take it with a grain of salt. Vol. 126, A merican Journal of M edicine. 2013. p. 951-5.

58. Santo K, Chow CK, Thiagalingam A, Rogers K, Chalmers J, Redfern J. M EDication reminder APPs to improve medication adherence in Coronary Heart Disease (M edApp-CHD) Study: A randomised controlled trial protocol. BMJ Open. 2017;7(10). 